\title{
Ninhos racionais para mamangava (Xylocopa frontalis) na polinização do maracujá-amarelo (Passiflora edulis)
}

\author{
Rational nesting box to carpenter bees (Xylocopa frontalis) in the pollination \\ of passionfruit (Passiflora edulis)
}

\author{
Breno Magalhães Freitas $^{12}$ José Hugo de Oliveira Filho ${ }^{3}$
}

\section{RESUMO}

\begin{abstract}
O Brasil é o maior produtor mundial de maracujá-amarelo (Passiflora edulis), porém apresenta baixas produtividades devido à carência de polinizadores naturais, como as abelhas mamangavas (Xylocopa spp.), nas áreas cultivadas. O presente trabalho investigou o uso, em cultivos de maracujá, de um modelo de ninho racional para mamangavas sugerido por FREITAS \& OLIVEIRA FILHO (2001). Os resultados mostraram que a presença dos ninhos racionais povoados na área estudada propiciaram aumentos da ordem de $505 \%$ na frequência das mamangavas às flores de maracujá e 92,3\% no vingamento inicial de frutos. Portanto, pode-se concluir que o uso das caixas racionais testadas é eficiente em aumentar a população dessas abelhas na área agrícola e que o seu uso pode contribuir para elevar os índices de polinização e produtividade do maracujá-amarelo.
\end{abstract}

Palavras-chave: mamangava, criatório racional, polinização, maracujá.

\section{ABSTRACT}

Brazil is the largest producer of passionfruit (Passiflora edulis) in the world, but holds low fruit productivity due to the lack of natural pollinators such as carpenter bees (Xylocopa spp.) in cultivated areas. The present work investigated the use in passionfruit plantations of a model of rational nesting box for carpenter bees suggested by FREITAS \& OLIVEIRA FILHO (2001). Results showed that the introduction of inhabited nesting boxes in the studied area raised in 505\% the frequency of carpenter bees to passionfruit flowers and in $92.3 \%$ initial fruit setting. Therefore, it is concluded that the use of this model of rational nesting boxes is efficient to increase carpenter bee population in an agricultural area and can contribute to increase levels of pollination and productivity in passionfruit plantations.

Key words: carpenter bee, rational rearing, pollination, passionfruit.

\section{INTRODUÇÃO}

As mamangavas (Xylocopa spp.) podem polinizar uma variedade de culturas agrícolas (CAMILLO, 1979; FREE, 1993; SIHAG, 1993; SOUSA, 1994; FREITAS et al., 1999; ALVES, 2000; FREITAS \& OLIVEIRA FILHO, 2001). Entre elas, o maracujá-amarelo (Passiflora edulis Sims. f. flavicarpa Deg.) destaca-se tanto por sua importância econômica para o País, como por depender diretamente da polinização cruzada para obtenção de frutos, tendo essas abelhas como o único polinizador eficiente de suas flores (RUGGIERO, 1973; 1980; 2000; MANICA, 1981; SOUSA, 1994).

O Brasil é atualmente o maior produtor mundial de maracujá-amarelo com aproximadamente 33 mil hectares plantados e produtividade média de 9.035kg.ha ${ }^{-1}$ (CANÇADO JÚNIOR et al., 2000; RUGGIERO, 2000). Porém, segundo RUGGIERO (2000) e AGRIANUAL (1998), a cultura do maracujá apresenta potencial produtivo no Brasil de 40.000 a $45.000 \mathrm{~kg} . \mathrm{ha}^{-1}$,

\footnotetext{
${ }^{1}$ Engenheiro Agrônomo, PhD., Professor do Departamento de Zootecnia, Universidade Federal do Ceará (UFC). Email:freitas@ufc.br Autor para correspondência.

${ }^{2}$ Departamento de Zootecnia, CCA, UFC, CP 12168, 60021-970, Campus do Pici, Fortaleza, CE.

${ }^{3}$ Engenheiro Agrônomo, M.Sc.
} 
se conduzida com irrigação e uso correto da polinização.

Uma série de fatores tem levado à redução no número de mamangavas nos maracujazais, com conseqüentes perdas de produtividade da cultura. A diminuição da cobertura vegetal próxima às áreas cultivadas, falta de locais adequados para nidificação, ausência de espécies silvestres nos plantios que funcionem como fonte de alimento e o uso de defensivos agrícolas vêm contribuindo para reduzir as populações dessas abelhas nos plantios comerciais para assegurar os níveis de polinização adequados (RUGGIERO, 1973; SAZIMA \& SAZIMA, 1989; CAMILLO, 2000; FREITAS \& OLIVEIRA FILHO, 2001). Como conseqüência, para tornar a cultura economicamente viável, a polinização manual vem sendo empregada em todo o país, aumentando consideravelmente os custos de produção (GRISI JÚNIOR, 1973; CEREDA, 1980; MANICA, 1981).

A introdução de mamangavas em áreas de maracujá dispensa a polinização manual e produz índices de polinização adequados, conforme demonstrado por CAMILLO (1996a,b). No entanto, a falta de ninhos racionais que permitam o manejo adequado das abelhas tem inviabilizado o criatório de mamangavas em escala comercial para a introdução em áreas agrícolas. FREITAS \& OLIVEIRA FILHO (2001) propuseram um modelo de caixa racional com ninhos móveis para mamangavas, e OLIVEIRA FILHO \& FREITAS (2003) testaram a colonização e biologia reprodutiva dessas abelhas no modelo proposto, verificando que ele apresenta boa aceitação por $\boldsymbol{X}$. frontalis, e não afeta a biologia reprodutiva dessa espécie de abelha. No presente trabalho, é testada a eficiência do uso dessas caixas racionais na polinização do maracujá-amarelo.

\section{MATERIAL E MÉTODOS}

A pesquisa foi conduzida na fazenda Sítio Estreito, município de São Luís do Curú - CE, situado $90 \mathrm{~km}$ ao Noroeste de Fortaleza, utilizando o modelo de caixa contendo ninhos racionais para mamangavas descrito em FREITAS \& OLIVEIRA FILHO (2001). Dados relativos à freqüência de pastejo das mamangavas nas flores, requerimentos de polinização do maracujazeiro e o efeito da introdução de ninhos racionais com mamangavas nos maracujazais foram avaliados nesse estudo.

\section{Freqüência de pastejo das mamangavas}

A freqüência diária de mamangavas às flores de maracujá, em uma área de 1ha, foi observada durante sete dias antes e sete dias depois da introdução de sete ninhos povoados em cinco caixas, com o objetivo de determinar a abundância natural dessas abelhas na área e o incremento da população após a introdução das caixas racionais povoadas. Isso foi feito percorrendo-se diariamente todas as fileiras do cultivo quando se anotava o número de mamangavas visitando as flores ou sobrevoando o pomar nos intervalos de 11:00 - 12:00h, 12:00 - 13:00h, 13:00 14:00h, 14:00-15:00h, 15:00-16:00h.

\section{Requerimentos de polinização do maracujá}

Para verificar os requerimentos de polinização do maracujazeiro, conduziu-se um experimento com os seguintes tratamentos:

$\mathrm{T}_{1}=$ Polinização livre - Cem flores de maracujá, escolhidas aleatoriamente antes de sua abertura, foram marcadas e após sete dias, contou-se e anotou-se o número dos frutos vingados. Esses dados possibilitaram determinar o nível de polinização ocorrendo naturalmente no pomar;

$\mathrm{T}_{2}=$ Polinização restrita - Neste tratamento, cem botões florais foram cobertos por sacos confeccionados com filó (malha $2 \mathrm{~mm}$ X $2 \mathrm{~mm}$ ). Ao abrirem, no dia seguinte, essas flores foram privadas da visita de agentes polinizadores pelos sacos de filó. Após sete dias, anotou-se o vingamento dos frutos;

$\mathrm{T}_{3}=$ Visita única sem remoção do pólen da flor - quarenta e um botões florais foram etiquetados e ensacados no dia anterior à antese. No dia seguinte, para cada flor, retirou-se o saco uma hora depois da flor estar aberta, quando os estigmas já haviam se curvado para a posição favorável à polinização e aguardou-se a visita da primeira mamangava. Após uma visita à flor, esta foi novamente ensacada. Cada flor foi acompanhada individualmente. Após sete dias, contou-se e anotou-se o número de frutos vingados;

$\mathrm{T}_{4}=$ Visita única com remoção do pólen da flor - quarenta botões florais foram ensacados, porém imediatamente após a antese o pólen das anteras foi removido por meio de hastes plásticas com pontas de algodão umedecidas, sendo o saco recolocado. Em seguida, procedeu-se como no tratamento anterior.

\section{Efeito da introdução de ninhos racionais com mamangavas}

O efeito da introdução de ninhos racionais povoados com mamangavas em áreas cultivadas com maracujá foi verificado comparando os resultados obtidos com aqueles da polinização livre antes da introdução das caixas na área, testando-se:

$\mathrm{T}_{1}=$ Polinização livre (antes da introdução das caixas) - cem flores de maracujá escolhidas 
aleatoriamente antes de sua abertura, foram marcadas. Após sete dias, contou-se e anotou-se o número de frutos;

$\mathrm{T}_{2}=$ Polinização com a introdução de colméias racionais para mamangavas - sete dias após a introdução de sete ninhos de mamangavas na área de cultivo de maracujá, marcaram-se cem flores da cultura, escolhidas aleatoriamente antes de sua abertura. Após sete dias, contou-se e anotouse o número de flores que vingaram.

\section{Tratamento estatístico}

Os dados relativos à freqüência de pastejo das mamangavas foram analisados por testes de Análise de Variância para cada um dos cinco horários estudados, e as médias comparadas $\boldsymbol{a}$ posteriori pelo teste de Tukey-B. Os dados referentes ao efeito da introdução de ninhos racionais com mamangavas nos pomares foram analisados por meio do teste não paramétrico de Kruskal-Wallis devido ao seu caráter binomial (vingou fruto $=1 \times$ não vingou $=$ 0 ), que não atende às pressuposições da ANOVA. As diferenças entre médias foram calculadas usando-se, também, testes não paramétricos de comparação múltipla. Já os dados sobre requerimentos de polinização do maracujazeiro foram testados por meio do teste de Mann-Whitney.

\section{RESULTADO}

\section{Freqüência de pastejo das mamangavas}

As observações feitas sobre a freqüência de pastejo das mamangavas, tanto antes quanto depois da introdução das caixas racionais no pomar de maracujá, mostram que o início das atividades de visitação às flores de maracujá por parte das mamangavas, ocorre por volta de $11 \mathrm{~h}$, momento em que é observada a abertura dos primeiros botões florais, prolongando-se até as $16 \mathrm{~h}$ (Tabela 1 ).

Houve diferenças significativas no número de abelhas visitando flores de maracujá ao longo do dia, tanto antes $\left(\mathrm{F}_{4,34}=13,224, \mathrm{P}<0,05\right)$ quanto depois $\left(\mathrm{F}_{4,34}=18,541, \mathrm{P}<0,05\right)$ da introdução de ninhos em colméias racionais (Tabela 1). Antes da introdução das colméias, a visitação das flores de maracujá por mamangavas silvestres mostrou que o número máximo de abelhas em atividade no pomar ocorreu nos intervalos de observação compreendidos entre 11 e 14h, que não diferiram entre si (Tabela 1). $O$ número de mamangavas nesses horários, no entanto, foi significativamente maior do que nas observações tomadas nos intervalos de tempo
Tabela 1 - Freqüência de pastejo de abelhas mamangavas (Xylocopa frontalis) antes e após a colocação dos ninhos no pomar

\begin{tabular}{lccc}
$\begin{array}{l}\text { Horário de } \\
\text { visita }(\mathrm{h})\end{array}$ & $\begin{array}{c}\text { Sem caixa } \\
(\mathrm{x} \pm \text { erro padrão })\end{array}$ & $\begin{array}{c}\text { Com caixa } \\
(\mathrm{x} \pm \text { erro padrão })\end{array}$ & Anova \\
\hline $11-12$ & $2,00 \pm 0,21 \mathrm{aB}$ & $5,00 \pm \mathrm{bA}$ & $\mathrm{F}_{1,13}=7,560$ \\
$12-13$ & $2,57 \pm 0,29 \mathrm{aB}$ & $13,57 \pm \mathrm{aA}$ & $\mathrm{F}_{1,13}=35,933$ \\
$13-14$ & $1,71 \pm 0,28 \mathrm{aB}$ & $15,57 \pm \mathrm{aA}$ & $\mathrm{F}_{1,13}=46,579$ \\
$14-15$ & $0,71 \pm 0,28 \mathrm{bB}$ & $4,00 \pm \mathrm{bA}$ & $\mathrm{F}_{1,13}=6,175$ \\
$15-16$ & $0,28 \pm 0,18 \mathrm{bB}$ & $1,71 \pm \mathrm{bA}$ & $\mathrm{F}_{1,13}=9,677$ \\
\hline
\end{tabular}

Valores seguidos da mesma letra minúscula nas colunas ou maiúsculas nas linhas não diferem a $\mathrm{P}<0,05$

entre 14 e 16h (Tabela 1). Observações feitas após a introdução das caixas racionais com ninhos de mamangavas, mostraram o mesmo padrão anterior exceto pelo fato de o número de mamangavas no pomar entre $11 \mathrm{e} 12 \mathrm{~h}$ ter diferido daquele no intervalo de maior pico entre as 12 e $14 \mathrm{~h}$, e não haver diferido significativamente dos horários de menor frequência a partir das 14h (Tabela 1).

\section{Requerimentos de polinização do maracujá}

$\mathrm{O}$ estudo dos requerimentos de polinização do maracujazeiro mostrou que o número de frutos vingados sete dias após a marcação das flores diferiram significativamente $\left(c^{2}=23,895 ; \mathrm{gl}=\right.$ $3 ; \mathrm{P}<0,05)$ entre os tratamentos. Uma única visita da mamangava em flores cujo pólen não havia sido removido, resultou em um maior número de frutos e diferiu significativamente $(\mathrm{P}<0,05)$ dos demais tratamentos (Tabela 2). Seguiram-se então, por ordem decrescente do número de frutos vingados, os tratamentos de uma visita da mamangava às flores cujo pólen havia sido totalmente removido, polinização livre e polinização restrita, todos diferindo entre si (Tabela 2).

Tabela 2 - Vingamento de frutos de maracujá sete dias após as flores terem sido submetidas à polinização livre, polinização restrita e uma visita da mamangava Xylocopa frontalis a flores com ou sem pólen.

\begin{tabular}{lccc}
\hline Tratamento & $\begin{array}{c}\mathrm{N}^{\mathrm{o}} \text { Flores } \\
\text { Total }\end{array}$ & $\begin{array}{c}\mathrm{N}^{\mathrm{o}} \text { Frutos } \\
\text { Vingados }\end{array}$ & $\%$ \\
\hline $\begin{array}{l}\text { Polinização livre } \\
\begin{array}{l}\text { Visita única da mamangava } \\
\text { sem remoção do pólen da flor }\end{array}\end{array}$ & 100 & 25 & $25,0 \mathrm{c}$ \\
$\begin{array}{l}\text { Visita única da mamangava } \\
\text { com remoção do pólen da flor }\end{array}$ & 40 & 28 & $68,3 \mathrm{a}$ \\
Polinização restrita & 66 & 0 & $47,5 \mathrm{~b}$ \\
\hline
\end{tabular}

Valores seguidos da mesma letra na coluna não diferem a $\mathrm{P}<0,05$ 


\section{Efeito da introdução de ninhos racionais com mamangavas}

$\mathrm{O}$ vingamento inicial de frutos no pomar diferiu significativamente (Mann-Whitney test $\mathrm{U}=$ $4400,0, \mathrm{P}<0,05)$ antes e depois da introdução das caixas racionais contendo ninhos de mamangavas (Tabela 3). A introdução das caixas racionais no pomar de maracujá levou a um incremento da ordem de $92,3 \%$ no vingamento inicial de frutos, quando comparado ao vingamento observado apenas com a visita das mamangavas silvestres.

\section{DISCUSSÃO}

Os dados encontrados neste trabalho sobre horário de forrageamento para mamangavas em maracujá estão de acordo com aqueles apresentados por CAMILLO (1979) e CAMILLO \& GARÓFALO (1982), que observaram o pico de forrageamento de $\boldsymbol{X}$. frontalis em torno das $13 \mathrm{~h}$. Esse fato também foi relatado por RUGGIERO (1980).

A introdução das caixas racionais com ninhos de mamangavas aumentou a população dessas abelhas e, conseqüentemente, o número de visitas às flores de maracujá em até $505 \%$ nos horários de maior freqüência, comprovando a eficiência dessas caixas em elevar a população residente de mamangavas nos pomares de maracujá. Infelizmente, não há outras investigações avaliando aumentos no número de mamangavas nas flores após sua introdução em pomares para comparações.

O tratamento de polinização restrita não vingou nenhum fruto, confirmando a necessidade da flor do maracujá de receber a visita de polinizadores para vingar o fruto, conforme preconizado por RUGGIERO (1973) e MANICA (1981). Além disso, as flores cujo pólen não foi removido apresentaram um vingamento superior a $68 \%$ quando visitadas apenas uma vez por uma mamangava, confirmando a importância atribuída por diversos estudos a esse inseto como polinizador da cultura do maracujá (GRISI JÚNIOR, 1973; CAMILLO, 1996a,b; SAZIMA \&

Tabela 3 - Vingamento dos frutos de maracujá sem a utilização da caixa racional e após a introdução da caixa racional contendo ninhos de Xylocopa frontalis.

\begin{tabular}{lccc}
\hline TRATAMENTO & $\begin{array}{c}\mathrm{N}^{\mathrm{o}} \text { Flores } \\
\text { Total }\end{array}$ & $\begin{array}{c}\mathrm{N}^{\mathrm{o}} \text { Frutos } \\
\text { Total }\end{array}$ & $\%$ \\
\hline Sem caixa racional & 100 & $13 \mathrm{~b}$ & 13,0 \\
Com caixa racional & 100 & $25 \mathrm{a}$ & 25,0 \\
\hline
\end{tabular}

Valores seguidos da mesma letra na coluna não diferem a $\mathrm{P}<0,05$.
SAZIMA, 1989; FREE, 1993; FREITAS, 1999; FREITAS \& OLIVEIRA FILHO, 2001).

$O$ vingamento de frutos como conseqüência de uma visita de mamangava a flores sem pólen, confirma a receptividade da flor do maracujazeiro ao pólen cruzado. Porém, o número significativamente $(\mathrm{P}<0,05)$ menor de frutos vingados nessa situação quando comparado ao tratamento, cujas flores possuíam pólen, sugere que a presença do próprio pólen na flor, apesar de auto-incompatível, é importante para um vingamento maior de frutos. Isso provavelmente ocorre porque o pólen aumenta a atratividade da flor para as mamangavas, estendendo o seu tempo de permanência na flor e, conseqüentemente, suas chances de transferir um maior número de grãos de pólen cruzados para os estigmas. Segundo FREE (1993) e FREITAS (1995), quanto maior for o tempo que o agente polinizador levar em cada visita a uma flor, maiores serão as possibilidades de ele transferir grãos de pólen viáveis, compatíveis e em quantidades suficientes para vingar o fruto de uma determinada espécie vegetal.

O incremento percentual da polinização no presente trabalho, apesar de significativo, está bem abaixo dos 700\% relatados por CAMILLO (1996a,b) após a introdução de 39 ninhos de $\boldsymbol{X}$. frontalis e $\boldsymbol{X}$. grisescens em um pomar de maracujá-amarelo com 1,5 ha, em Holambra - SP. No entanto, é importante ressaltar que esse resultado significou um aumento na porcentagem de flores vingadas de 3,2\% para $25,0 \%$. Na presente investigação, os mesmos $25 \%$ de vingamento foram alcançados, sendo que a acentuada diferença no incremento do percentual de flores vingadas observada entre os dois trabalhos foi devido ao nível de polinização inicial em nossa investigação ter sido de $13,0 \%$. Isso confirma FREITAS $(1995 ; 1998)$, segundo o qual, o incremento de polinização em uma determinada cultura não depende apenas da eficiência com que o serviço de polinização é realizado pelo agente polinizador, mas também dos índices naturais de polinização da área antes da introdução de abelhas.

Aparentemente, $25 \%$ de polinização das flores de maracujá parece ser o patamar superior alcançado pelas mamangavas. Dessa forma, pode-se constatar que a caixa racional para mamangavas produziu resultados de polinização tão eficientes quanto aqueles de CAMILLO (1996a,b).

\section{CONCLUSÃO}

Conclui-se que o uso das caixas racionais povoadas com mamangavas é eficiente em aumentar a 
população dessas abelhas na área agrícola e que o seu uso contribui para o aumento dos índices de polinização e produtividade do maracujá-amarelo.

\section{REFERÊNCIAS BIBLIOGRÁFICAS}

AGRIAnUal 98. Anuário Estatístico da Agricultura Brasileira. São Paulo : FNP Consultoria \& Comércio, 1988. $481 \mathrm{p}$.

ALVES, J.E. Eficiência de cinco espécies de abelhas na polinização da goiabeira (Psidium guajava). 2000. $82 \mathrm{f}$ Dissertação (Mestrado em Zootecnia) - Universidade Federal do Ceará.

CAMILlO, E. Aspectos ecológicos e evolutivos de abelhas do gênero Xylocopa (Hymenoptera, Anthophoridae). 1979. 173f. Dissertação (Mestrado em Ecologia e Recursos Naturais) - Universidade Federal de São Carlos.

CAMillo, E. Utilização de espécies de Xylocopa (Hymenoptera, Anthophoridae) na polinização do maracujá amarelo. In: ENCONTRO SOBRE ABELHAS, 2., 1996 , Ribeirão Preto. Anais... Ribeirão Preto : Universidade de São Paulo, Faculdade de Filosofia Ciências e Letras de Ribeirão Preto, 1996a. p.141-146.

CAMILlo, E. Polinização do maracujá amarelo. In: CONGRESSO BRASILEIRO DE APICULTURA, 11., 1996, Teresina. Anais... Teresina : Confederação Brasileira de Apicultura, 1996b. p.317-321.

CAMILlO, E. Polinização do maracujazeiro: mamangavas $\mathrm{x}$ africanizadas. In: CONGRESSO BRASILEIRO DE APICULTURA, 13., 2000, Florianópolis. Anais... Florianópolis : Confederação Brasileira de Apicultura, 2000. $1 \mathrm{CD}$.

CAMILlO, E.; GARÓFALO, C.A. On the bionomics of Xylocopa frontalis (Olivier) and Xylocopa grisescens (Lepeletier) in southern Brazil. I. Nest construction and biological cycle. Revista Brasileira de Biologia, Rio de Janeiro, v.42, p.571-582, 1982.

CANÇADO JÚNIOR, F.L.; ESTANILAU, M.L.L.; PAIVA, B.M. de Aspectos econômicos da cultura do maracujá. Informe Agropecuário, Belo Horizonte, v.21, n.206, p.10-17, 2000.

CEREDA, E. Tratos culturais. In: RUGGIERO, C. (Ed). Cultura do maracujazeiro. Jaboticabal : FCAV, 1980. p.33-45.

FREE, J.B. Insect pollination of crops. Londres : Academic, 1993. 684p.

FREITAS, B.M. The pollination efficiency of foraging bees on apple (Malus domestica Borkh) and cashew (Anacardium occidentale L.). 1995. 197f. Tese
(Doutorado em Apicultura) - University of Wales, Cardiff, Grã-Bretanha.

FREITAS, B.M. O uso de programas racionais de polinização em áreas agrícolas. Mensagem Doce, São Paulo, v.46, p.1620, 1998.

FREITAS, B.M. A vida das abelhas. Fortaleza : UFC: Craveiro \& Craveiro, 1999. CD-ROM.

FREITAS, B.M.; OLIVEIRA FILHO J. H. Criação racional de mamangavas para polinizaça em áreas agrícolas. Fortaleza : Banco do Nordeste, 2001. $96 \mathrm{p}$

FREITAS, B.M. et.al. Pollination requirements of West Indian cherry (Malpighia emarginata) and its putative pollinators. Journal of Agricultural Science, Cambridge, v.133, p. 303 $311,1999$.

GRISI JÚNIOR, C. Método de polinização artificial do maracujazeiro (Passiflora edulis). In: CONGRESSO BRASILEIRO DE FRUTICULTURA, 2., 1973, Viçosa. Resumos... Viçosa : Sociedade Brasileira de Fruticultura, 1973b. p. $433-436$.

MANICA, I. Fruticultura tropical: 1. Maracujá. São Paulo : Agronômica Ceres, 1981. 160p.

OLIVEIRA FILHO, J.H.; FREITAS, B.M. Colonização e biologia reprodutiva de Xylocopa frontalis em um modelo de ninho racional. Ciência Rural, v.33, n.4, p.693-697, 2003 .

RUGGIERO, C. Estudos sobre floração e polinização do maracujá amarelo (Passiflora edulis f. flavicarpa Deg.). 1973. 92f. Tese (Doutorado em Ciências) - Faculdade de Medicina Veterinária e Agronomia de Jaboticabal.

RUGGIERO, C. Alguns fatores que podem influir na frutificação do maracujazeiro. In: RUGGIERO, C. (Ed). Cultura do maracujazeiro. Jaboticabal : FCAV, 1980 p. 55-63.

RUGGIERO, C. Situação da cultura do maracujazeiro no Brasil. Informe Agropecuário, Belo Horizonte, v.21, n.206, p.59, 2000 .

SAZIMA, I.; SAZIMA, M. Mamangavas e irapuás (Hymenoptera, Apoidea): visitas, interações e conseqüências para polinização do maracujá (Passifloraceae). Revista Brasileira de Entomologia, São Paulo, v.33, n.1, p.109$118,1989$.

SIHAG, R.C. Behaviour and ecology of the subtropical carpenter bee, Xylocopa fenestrata F.6. Foraging dynamics, crop hosts and pollination potential. Journal of Apicultural Research, Cardiff, v.32, n.2, p.94-101, 1993.

SOUSA, P.J.S. Polinização em maracujazeiro. In: SÃO JOSÉ, A.R. (Ed). Maracujá: produção e mercado. Vitória da Conquista : DFZ/UESB, 1994. p.65-70. 